\title{
CLINICAL AND LABORATORY PECULIARITIES OF CHILDREN'S STATE WITH CHRONIC TONSILITIS ON TYPE 1 DIABETES
}

DOI: 10.36740/WLek202007128

\author{
Yurii V. Gavrylenko ${ }^{1}$, Andriy A. Laiko ${ }^{1}$, Oleg F. Melnikov' ${ }^{2}$, Lilia M. Rudenko ${ }^{3}$, Tatiana M. Osadcha ${ }^{3}$ \\ 'SHUPYK NATIONAL MEDICAL ACADEMY OF POSTGRADUATE EDUCATION, KYIV, UKRAINE \\ INSTITUTE OF OTOLARYNGOLOGY NAMED BY PROF. AS KOLOMIYCHENKO NAMS OF UKRAINE, KYIV, UKRAINE \\ ${ }^{3}$ NATIONAL PEDAGOGICAL DRAGOMANOV UNIVERSITY, KYIV, UKRAINE
}

\begin{abstract}
The aim: Improvement of early diagnostics quality and efficiency of chronic pharyngeal diseases (CPD) treatment in children with DM-1 by studying the clinical and laboratory features of the disease course and complex therapy administration.

Materials and methods: A comprehensive examination of 707 children with diabetes mellitus-1, aged 3 to 18 , was conducted, which determined clinical and laboratory features of their state in the presence and absence of chronic tonsillitis (CT).

Results: Using microbiological and cytological examination of the palatine tonsils (PT) crypts, the leading role of microbial associations in the pathogenesis of HT in the formation of immune inflammation was determined, their influence on the local immunity indices was defined. Significant disturbances of the microcirculatory bed (MCB) in the presence of HT in children with DM-1, direct correlation between CPD and the presence of vascular glomeruli, changes in the retinal capillary structure $(r=0,332 ; p<0,05)$ according to biomicroscopy bulbar conjunctiva (BMBC) data were determined. The study of psycho-emotional state in children with CT and DM- 1 was conducted, along with applied psycho-corrective program, which significantly reduces the manifestations of aggressiveness, aggression, and frustration reactions in them.

Conclusions: A non-invasive complex of the study of PT state on changes of local immunity indices, microbiocenosis and cytological data for correction of CPD course was developed, which allows to obtain faster compensation of $\mathrm{CT}$ and contributes to patients' quality of life improvment.
\end{abstract}

KEYWORDS: chronic tonsillitis, children, palatine tonsils, type 1 diabetes

Wiad Lek. 2020;73(7):1465-1469

\section{INTRODUCTION}

The incidence of CT, which is especially prevalent among children aged 6 to 17, attracts the increased attention of otolaryngologists with frequent recurrences, development of complications and its influence on diseases of other organs and systems, despite the wide arsenal of modern methods of treatment $[1,2,3]$.

Of particular importance is the CT of comorbid course with such autoimmune endocrine disease as DM-1. Disorders of the functional state of PT at CT in children with diabetes mellitus- 1 are closely related to the level of glycemic control (GC) and are manifested by increased susceptibility to infections, increased cell adhesion of microorganisms, the presence of micro- and macroangiopathy, neuropathy $[4,5]$.

It also affects the antibodies synthesis, the phagocytic activity of macrophages and leukocytes, the barrier function of the mucous membranes and the regenerative capacity of all tissues, which generally inhibits local defense mechanisms with a decrease in the overall immunoreactivity of the organism $[6,7]$.

The problem of diseases of ENT-organs in children with diabetes mellitus type 1 (DM-1), has not been studied and is currently relevant and needs urgent solution. According to the literary sources, there are only a few scientific papers on some diseases of ENT-organs in adults with diabetes mellitus-1. Therefore, we have conducted scientific research for the time in Ukraine, which is devoted to the study of CPD problem in children with DM-1.

\section{THE AIM}

The aim of the work is to improve early diagnostics quality and efficiency of chronic pharyngeal diseases (CPD) treatment in children with DM-1 by studying the clinical and laboratory features of the disease course and complex therapy administration.

\section{MATERIALS AND METHODS}

During 2013-2018, 707 patients with DM-1 who were hospitalized at the endocrinological wards of the National Children's Specialized Hospital «Ohmatdet» of the Ministry of Health of Ukraine and the City Endocrinological Department of the Children's Clinical Hospital No. 6 of Kyiv were examined. The age of the patients ranged from 3 to 18,365 boys (51.6\%), 342 girls (48.4\%), the average age was $(10.9 \pm 0.4)$ years.

The main study group consisted of 238 children with CT on the background of DM-1, and comparative groups included children with DM-1 without CT $(n=60)$ and pa- 
tients with CT without DM-1 $(\mathrm{n}=20)$. The control group included 20 practically healthy individuals. The distribution of patients by gender and age in all compared groups was similar in terms of indiced and initial clinical characteristics.

Microbiological and cytological research was conducted in accordance with the current regulatory documents by accredited methods; quantitative assessment of microbiocenosis was defined on the basis of penetrance indices, population level of bacteria when calculating colony forming units in $1 \mathrm{~g}$ of material (lg CFU / g).

Immunological research methods were carried out in accordance with current guidelines and instructions of the manufacturer of the reagents. Calculation of the concentration of immunoglobulins was carried out by the enzyme immunoassay on the Stat Fax 2100 analyzer (USA): the content of secretory immunoglobulin A ( $I I A$ ), the level of $\alpha$-interferon ( $\alpha$-INF) by the enzyme immunoassay (Vector Best, Russia) were studied; concentration of interleukin $1 \beta$ $((\mathrm{L}-1 \beta)$, lactoferrin was studied by enzyme-linked immunosorbent assay (Protein Contour LLC, Russia).

The study of the MCB status in children with DM-1, and its influence on the development and course of CPD was carried out by defining the nail bed capillaroscopy (NBC) indices according to the standard method, biomicroscopy of the bulbar conjunctiva (BMBC), which was assessed by using slit cleft followed by photoregistration of vessels and microrinoscopy (MCRS). The results of the BMBC examination included the assessment of the caliber of microvessels, their course, myandric tortuosity of capillaries, venules, arterioles, arterial-venous ratio, number of functioning capillaries, size of vascular patches, rate and transparency of blood vessels, degree of transparency of blood vessels, degree of transparency, perivascular edema, hemorrhage, sweet phenomenon.

The credibility of differences between the comparison groups was determined by the Student's parametric criterion and the non-parametric Mann-Whitney test. The difference between the indices was considered reliable at $p$ $<0.05$. Fisher's angular transformation method was applied to detect differences between the two groups with minimum sample values and to compare with the qualitative indices expressed as a percentage.

Correlation and multivariate analysis of the researched indices was carried out with the calculation of the Pearson correlation coefficients (r). Statistical calculations were performed by IBMSPSS 17.0 software, Statistic 8, Microsoft Office Excel 2010.

The experts session of the Ethics Committee of the Shupyk National Medical Academy of Postgraduate Education approved this clinical study and gave permission to conduct it in accordance with the current legislation of Ukraine, modern ethical standards and principles of conducting clinical research (Minutes of the session of the Ethics Committee №10 dated 06/10/2014).

\section{RESULTS}

According to the results of otorhinolaryngological examination of children with diabetes mellitus-1, the structure of diseases of ENT organs specific for them was obtained. The largest group among them was patients diagnosed with CPD $(\mathrm{n}=424)$ : the largest group of children with CT $(238 ; 56.2 \%)$, consisting of 136 boys, 102 girls aged 6-18. Hypertrophy of adenoid vegetations was diagnosed in $21.2 \%(\mathrm{n}=90)$ of the examined, hypertrophy of the tonsils $-8 \%(\mathrm{n}=34)$, chronic adenoiditis $-7.5 \%(\mathrm{n}=32)$, chronic pharyngitis $-7.1 \%(\mathrm{n}=30)$.

We have found a non-angina form of $\mathrm{CT}$, which is more commonly diagnosed in older school-age children (34.8\%) than younger children (26.9\%). Roller-like thickening of the edges of the anterior and posterior palatal brackets was established in $77.6 \%$ of younger school-age children versus $74.4 \%$ - older, a congestive hyperemia stripe in the front brace $-64.4 \%$ versus $34.8 \%$, the presence of scar adhesions between the tonsils and palatine brackets $-73,6 \%$ versus $43,0 \%$, the presence of caseous plugs in the lacunae of TC during rotation in children aged 6-12 is significantly $(\mathrm{p}<0,05)$ higher $(71,0 \%)$ compared with patients aged 13-18 (44, 1\%), however, the presence of liquid pus in PT lacunas during rotation in them is significantly $(\mathrm{p}<0.05)$ lower (7.9\%) compared with patients aged 13-18 (23.2\%), augmentation and consolidation of regional lymph nodes in children of both groups were not significantly different (47.3\% versus $56.9 \%)$.

Diagnosis of DM-1 was established by doctors of the endocrinological department, who were assessing GC state in the examined children by determining glycated hemoglobin (Hbals (\%)) and indices of glycemia. The ground for grouping by GC level was based on the value of НbАлc (\%) in accordance with the Protocol of providing medical care to children with diabetes (Order of the Ministry of Health of Ukraine No. 254 of 27.04.2006). Optimal (GCO) was considered in the case of the level of HbALs in the range of 6-7,9\%, suboptimal (GCSO) - 7,9-9\%, high-risk GC (GCHR) - more than 9\%. Glucose levels in the exemined patients ranged from $3.8 \mathrm{mmol} / 1$ to $17.2 \mathrm{mmol} / \mathrm{l}$ (average $10.5 \mathrm{mmol} / \mathrm{l}$ ). In $63.2 \%$ of the examined children, GCHR was observed, $24.4 \%$ of the examined children had GCSO, and only $12.4 \%$ of them had GCO.

Microbiological studies of PT lacunae revealed that the studied microbiocenoses in children with DM-1 mainly consisted of mono- and multicomponent associations of aerobic and facultative anaerobic microflora. 2-3-component associations were found to be 2.5 times more frequent in CT in patients with DM-1 than in individuals with DM-1 without CT. According to the research done, no significant differences were observed between the persistence of microbiocenoses consisting of 2-3 microorganisms in the main and comparative groups, however, microbiocenoses that included 2 or more representatives were detected in $50 \%$ of patients in both groups $(\mathrm{p}<0,05)$.

Representatives of the enterococci Klebsiella, Enterobacter, E. coli persisted in the children of the main group much more often than in comparative group patients, in an amount exceeding lg $3 \mathrm{CFU} / \mathrm{g}$. This was especially true of children in the main group, where the Klebsiella pneumonie strain was sown 3.5 times more often than in 
the comparative one. Given pathogen was sown in $22 \%$ of cases in the amount of $\lg 4.01-5.41 \mathrm{CFU} / \mathrm{g}$. Yeast mushroom colonization in both groups was represented equally in the amount of $\lg 3.5 \mathrm{CFU} / \mathrm{g}$.

According to the results of the cytological study from the PT lacunae in children of the main group, the following cytomorphological features were identified.

1. The low level of cellular composition indices - characterized by a moderate or high degree of desquamation of the flat epithelium with the signs of cell proliferation and degenerative changes. Giant multinucleated cells of chronic inflammation are detected. Neutrophilic leukocytes with incomplete phagocytosis of bacteria are in large numbers. Macrophage locations are found. Histiocytes are in small numbers. Lymphocytes are rare or absent. The bacterial flora is mixed, in particular spirochetes, fusobacteria are in large numbers, fungus are present.

2. The average level of cellular composition indices - the preparation is dominated by active lymphocytes, part in a state of ballast transformation. Plasmacytes are present, separately and in clusters. Neutrophilic leukocytes are in small numbers. Cells of the flat epithelium, individually and in layers are in small numbers. Mixed bacterial flora is in a small amount.

3. The high level of cellular composition indices- characterized by a large number of active lymphocytes in the preparation content, separately and in clusters, partly in a state of ballast transformation, places of mitotically divided cells. Neutrophilic leukocytes are in small numbers. Plasmocytes are present, separately and in clusters. Moderate desquamation of the flat epithelium is observed. Mixed bacterial flora is in a moderate amount. Cytological data analysis in children of the main group, considering GC level, has found a statistically significant difference $(\mathrm{p}<0.01)$ in reduction of high level in cell composition (5.3\%) compared with the average (45.6\%) and low (49.1\%) levels at GCHR. A similar tendency was observed at GCSO, where a high level of cellular composition (12\%) was significantly $(\mathrm{p}<0.05)$ reduced compared with average (36\%) and low (52\%) levels. At CT in children with DM-1 and GKO, the indice of high cellular composition is significantly lower (7.6\%) compared with the average (46.3\%) and low $(46.1 \%)$ levels $(\mathrm{p}<0.05)$.

Regarding the course of CT with frequent and rare exacerbations in children with DM-1, the following features of the cytological state have been identified. In patients with CT and frequent exacerbations on the background of DM-1, the high level indice of cellular composition was reduced $(5.1 \%)$ and had a statistically significant difference ( $\mathrm{p}<0.01)$ compared with the moderate $(45.7 \%)$ and low $(48,2 \%)$ levels. At CT with rare exacerbations (up to 3 times), the high level of cellular composition was also significantly $(\mathrm{p}<0.05)$ lower $(12.4 \%)$ compared with the moderate (40.1\%) and low (47.5\%) levels.

We have conducted immunological research of local immunity and found that humoral mechanisms of oropharyngeal secretion (OPS) protection at CT in children with
DM-1 also had specific features. Thus, the concentration of sIgA in OPS of children with DM-1 was higher than normal $(57-260 \mu \mathrm{g} / \mathrm{ml})$, the lactoferrin content in the main group was lower $(9224 \mathrm{ng} / \mathrm{ml})$ compared with the children of the control group (10858 ng / ml), and the concentration of $\alpha$-INF in OPS in patients of the main group was $12.0 \mathrm{pg} / \mathrm{ml}$, which was significantly higher- more than twice than in the comparative group $(7.8 \mathrm{pg} / \mathrm{ml})(\mathrm{p}<0.05)$, however, the level $\gamma$-INF in children of the main $(332 \mathrm{pg} / \mathrm{ml})$ and comparative (322 pg / ml) groups had no significant differences. The level of proinflammatory -L- $1 \beta$ in OPS of the children of the main group $(49.9 \mathrm{pg} / \mathrm{ml})$ was twice lower than in the comparative group $(108.4 \mathrm{pg} / \mathrm{ml})(\mathrm{p}<0.05)$, and the concentration of lysozyme in the OPS in patients with CT and with DM-1 was $3.0 \mu \mathrm{g} / \mathrm{ml}$ compared with $2.1 \mu \mathrm{g} / \mathrm{ml}$ in the comparative group.

In the study of MCB state indices in the group of patients examined, it was found that less than $1 / 3$ of children with CT on the background of DM-1 have a normal capillary structure in contrast to half of the patients in the comparative group $(p<0.05)$. In addition, there was a clear tendency of the increase of the patients number with severe microcirculatory disorders in the main group. II-III degrees of MCB disorders in children of the main group were detected in $22.5-27.5 \%$ of cases, while in comparative group II degree was $14.5 \%$, III - only $7.1 \%(\mathrm{p}<0.05)$. which is 3 times less than with the $\mathrm{CT}$ presence.

In assessing the results of BMBC in patients with DM -1 , the dependence of vascular disorders from the nature of ENT pathology was detected, especially at CPD. Thus, in the presence of CT in children on the background of CD-1 vascular disorders in the form of irregularity of the caliber of vessels (45\%), single microanurysms (65\%), myandric tortuosity of capillaries (80\%) and venules (50\%), single arterio-venular anastomoses (35\%) were revealed. Extravascular abnormalities in the form of microhemorrhages $(15 \%)$ and perivascular edema (10\%) were also observed.

We found that with longer duration of disease ((3.68 \pm $0.05) ; \mathrm{p}<0.05)$ in children with CD-1, in $75.3 \%$ of cases chronic pathology of ENT-organs prevails, among which $\mathrm{CT}$ is the leading place (48.5\%). While studying the assessment of the severity of DM-1 by the level of GC, the influence of CPD on the increase of HbAls was found in the examined children, with $61.4 \%$ of such patients having a GCHR level.

According to the data of conducted correlation analysis of changes in MCB indices, a direct connection between the presence of chronic ENT pathology and vascular glomeruli $(r=0,529 ; p<0,05)$, changes in the retinal capillary structure $(r=0,332 ; p<0,05)$ according to $B M B C$ data, GC levels and the presence of abnormal mucous vessels of the NS mucosa $(r=0.488 ; p<0.05)$ was detected in patients with DM-1, which confirms the negative influence of the underlying disease on disorders of $\mathrm{MCB}$, especially in the presence with CT.

According to BMBC data, a direct correlation between MCRS indices was detected, such as mucosal dryness, and the presence of multiple microangiopathies $(r=0.349$; 
$p<0.05)$, venous sacculation $(r=0.320 ; p<0.05)$, between the abnormal vessels and the presence of vascular glomeruli $(\mathrm{r}=0.459 ; \mathrm{p}<0.05)$, irregularity of the vessels caliber $(\mathrm{r}=$ $0.329 ; \mathrm{p}<0.05)$, venous sacculation $(\mathrm{r}=0.375 ; \mathrm{p}<0.05)$. In addition, the indice of capillary misalignment was directly correlated with the presence of vascular glomeruli $(\mathrm{r}=$ 0.378 ; $\mathrm{p}<0.05)$.

Extravascular abnormalities in the form of hemorrhages, which was detected at MCRS in the children of the main group were significantly correlated with the meandric tortuosity of the capillaries $(\mathrm{r}=0.314 ; \mathrm{p}<0.05)$ and the presence of abnormal vessels $(r=0.378 ; \mathrm{p}<0.05)$.

Research data of the psycho-emotional state of patients with CT on the background of DM-1 found the presence of aggression mainly against adults (76.2\%), low self-esteem (66.7\%), fatigue, exhaustion (64.3\%), and 56, 8\% of children experienced fears, feelings of insecurity and anxiety. Only $17.3 \%$ of patients had a positive emotional state, characterized by emotional satisfaction, desire to communicate.

Having analyzed the results obtained in the examined children with CT and DM-1, we concluded that it is necessary to apply a psycho-corrective program for this category of individuals. After conducting the corrective program in patients according to our method, the average aggressiveness in the children of the main group decreased significantly $(p<0,05)$ from $81,6 \%$ to $26,6 \%$, which was not observed in the compative group; manifestations of verbal (from $37.8 \%$ to $17.7 \%$; $\mathrm{p}<0.05$ ) and spontaneous (from $24.4 \%$ to $13.3 \%$; $\mathrm{p}<0.05$ ) agression significantly decreased the number of times. Also in the main group aggressive self-defense (from $37.8 \%$ to $11.1 \%$; $<<0.05$ ) and indicators of frustration reactions (from $64.4 \%$ to $24.4 \%$; $p<0.01$ ) decreased, but no significant changes were observed in the children of the comparative group.

\section{DISCUSSION}

The fact that the value of GC level (HbAlc) at CT in the patients of the main group is statistically significantly bigger than the corresponding value in the comparator may indicate a significant worsening of the DM-1 course in children with CT.

The insemination of PT with gram-positive coccal flora with high biological activity in such patients is indisputable, however, conditionally pathogenic bacteria value with pronounced persistent potential, which is combined with high indices of colonization intensity, increases in them.

The microbiocenotic peculiarities of PT in children of the main group which were investigated and revealed by us indicate the necessity and expediency of inclusion of methods and antiseptic agents in the regimens of treatment that have a directed antimicrobial effect, and can also ensure the restoration and preservation of normal microbiocenosis of PT.

It should be noted that cytological study of the content of PT lacunas at CT in children with DM- 1 conducted by us is an additional informative method for assessing the state of PT. The content of the crypt is a source of constant antigenic and mitogenic stimulation necessary to support the body's immunological homeostasis. Research of the cellular composition of smears from lacunae, especially in cases with no pronounced clinical symptoms, allows the otolaryngologist to define the form of CT more accurately, to assess the effectiveness of the performed conservative treatment.

However, conducting such a standard bacteriological and cytological research in children with DM-1 has certain complicated features, given the physiological and psychological characteristics of such patients. At the same time, the high percentage of identification of characteristic changes in PT state, the speed and convenience of its conducting make it possible to consider this method as promising for the screening of PT state disorders for an earlier beginning of treatment and rehabilitation measures. [8]

Changes in local immunity revealed by us in the research of OPS at CT in children on the background of CD-1 showed a pronounced immunological deficiency that requires correction. The role of immune mechanisms, in particular chronic inflammation, in the development of DM-1 and its vascular complications has been actively discussed in recent years. The presence of chronic inflammation in PT in these patients suggests that this process is directly related to the violation of the immune status and the formation of early complications. Immune system cells (lymphocytes, monocytes) and endothelium are involved in the development of the inflammatory process, while at the same time intercellular interactions are performed by adhesion molecules, cytokines, and growth factors. $[9,10]$ Therefore, immunoinflammatory reactions are involved in the development of autoimmune destruction of pancreatic islets at DM-1, as well as in the formation of microangiopathy.

Therefore, the study of MCB status in the comorbid course of CT in children with DM-1 is an important step in the laboratory research, which complements the findings of previous researchers. [11]

Thus, the data of our correlation analysis proved that at CT in children on the background of DM-1, infectious-inflammatory changes of the mucous membrane of the NS lead to disorders of the peripheral trophic of its tissues and worsen the MCB, which requires early diagnosis and administration of effective therapy.

The data of examination of the psycho-emotional state of patients with CT on the basis of the psycho-diagnostic methods used by us, considering the severity and duration of DM-1 disease, confirmed the opinion of specialists that significant changes in the emotional sphere are taking place in such patients. [12]

Therefore, this contingent of patients, especially those ones belonging to the group with low level of adaptation, requires special psychological support.

\section{CONCLUSIONS}

At $C T$ in children with CD-1, the density of microbial insemination of PT lacuna is $\lg (3.86 \pm 0.78) \mathrm{CFU} / \mathrm{g}$ compared to patients with DM-1 without CT ( $\lg (3.35 \pm 0.43) \mathrm{CFU} / \mathrm{g}$; $\mathrm{p}=0.05$ ). Microbiocenoses of TC, which include 2 or more representatives of conditionally pathogenic microorganisms, 
are credibly detected in $50 \%$ of the children of the main group compared with the comparative $(\mathrm{p}<0.05)$, and their species composition is expanded due to the persistence of Staphylococcus aureus (61\%), Klebsiella pneumonie (22\%), Streptococcus pyogenes (12\%).

Specific cytologic features of the content of PT lacunas at CT in children on the background of DM-1 with GCHR are a significant $(\mathrm{p}<0.01)$ increase oflow $(49.1 \%)$ and medium $(45.6 \%)$ levels of cellular composition compared with high $(5,3 \%)$ cell level.

Humoral mechanisms of OPS protection in children with CT and DM-1 are distinguished by a decrease in the level of sIgA, lactoferrin, and a twofold decrease in the level of a-INF compared with the comparative group, indicating an immunological imbalance that requires correction.

Based on the correlation analysis of microcirculation indices, a direct correlation between the presence of chronic ENT pathology and changes in the retinal capillary structure $(r=$ $0.332 ; \mathrm{p}<0.05)$ was detected according to BMBC data. A direct correlation between the level of GC and the presence of abnormal vessels of the nasal septal mucosa $(r=0.488 ; p<0.05)$ at $\mathrm{HT}$ in children with DM-1 confirms the negative influence of the underlying disease on the disorder of the MCB state.

Psycho-emotional disorders in children with CT on the background of DM-1 are characterized by the presence of fears, feelings of insecurity and anxiety in $56.8 \%$ of patients, fatigue and exhaustion- $64.3 \%$, low self-esteem $66.7 \%$. The identified changes require the application of a psycho-correction program that can successfully improve theipatients' psychological state.

Considering the above results of our research, the study of CPD in children on the background of DM- 1 is expedient and has important social and practical value in clinical medicine. That is the multidisciplinary approach and the cooperation of specialists of different profiles that will significantly improve the quality of life of children suffering from CT and DM-1.

\section{REFERENCES}

1. Laiko A.A. Ditjacha otorhinolaryngologija [Pediatric Otorhinolaryngology]. Laiko A.A., Kosakovskij A.L., Zabolotna D.D. et al. Kiev: Logos; 2013, p. 575. (In Ukrainian).

2. Windfuhr J., Toepfner N., Steffen G. et al. Clinical practice guidline: tonsillitis 1. Diagnostics and nonsurgical management. Eur Arch Otorhinolaryngol. 2016; 273: 974-989.

3. Melnikov 0.F. Immunologiya chronicheskogo tonzillita [Immunology of Chronic Tonsillitis]. Melnikov 0.F., Zabolotny D.I., Kischuk V.V. et al. Kiev: Lodos; 2017, p 192. (In Ukrainian).

4. Gordin D., Forsblom C. Acute hyperglycaemia induces an inflammatory response in young patients with type 1 diabetes. Ann Med. 2008; 40 (8): 627-633.

5. Lo H.Ch., Lin S.Ch. The relationship among serum cytokines, chemokine, nitric oxide, and leptin in children with type 1 diabetes mellitus. Clinical Biochemistry. 2004; 37: 666-672.

6. Gurov A., Biryukova E., Yushkina M. Sovremennye problemy diagnostiki i lecheniya gnoyno-vospalitel'nykh zabolevaniy LOR-organov u bol'nykh sakharnym diabetom [Modern problems of diagnosis and treatment of inflammatory diseases of upper respiratory tract in patients with diabetes]. Vestnik otorinolaringologii. 2011; 2: 76-79. (In Russian).
7. Zieliński Ł.P., Smith A.C., Smith A.G. et al. Metabolic flexibility of mitochondrial respiratory chain disorders predicted by computer modelling. Mitochondrion. 2016; 31: 45-55.

8. Laiko A.A., Gavrylenko Y.V., Volgina I.E. The functional state of the tonsils in children with type 1 diabetes. ScienceRise. 2016;1(3):71-6.

9. Budrejko 0.A., Morozov 0.V., SHlyahova N.V. et al. Osoblivosti produkcii sudinnogo endotelial'nogo faktora rostu (VEGF) u ditej z cukrovim diabetom 1 tipu [Features of vascular endothelial growth factor (VEGF) production in children with type 1 diabetes]. Ukr. zhurn. dit. endokrinologiï. 2014;(3):14-8. (In Ukrainian).

10. Levkovich M.A., Galkina G.A., Voropaj A.A. Immunopatogenez sosudistyh oslozhnenij pri saharnom diabete u detej. Citokiny i vospalenie. [Immunopathogenesis of vascular complications in diabetes mellitus in children. Cytokines and inflammation.] 2014;(3):115-6. (In Russian).

11. Rossing $P$. The changing epidemiology of diabetic microangiopathy in type 1 diabetes. Diabetologia. 2005;48(8):1439-44.

12. Nikiforova E.M., Konovalenko N.V. Osobennosti psihoemocional'nogo statusa u detej, stradayushchih saharnym diabetom tipa 1. Volgogr. nauch.-med. zhurn. [Features of psycho-emotional status in children suffering from type 1 diabetes]. 2011;(2):31-3. (In Russian).

The research was carried out within the framework of the research work of the Department of Pediatric Otorhinolaryngology of the Shupyk National Medical Academy of Postgraduate Education, Kyiv, Ukraine - "Diagnosis and treatment of diseases of ear, throat and nose in children" (State registration number 0113U002213).

\section{ORCID and contributionship:}

Yurii V. Gavrylenko: 0000-0002-1688 -7449 A,B,C,D,F

Andriy A. Laiko: 0000-0002-9782-9370 A,E,F

Oleg F. Melnikov: 0000-0002-1261-8647 C,E,F

Lilia M. Rudenko: 0000-0003-1655-5708 ${ }^{E, F}$

Tatiana M. Osadcha: 0000-0001-5632-8716 ${ }^{B, D}$

\section{Conflict of interest:}

The Authors declare no conflict of interest.

\section{CORRESPONDING AUTHOR} lurii V. Gavrylenko

Shupyk National Medical Academy of Postgraduate Education

9 Dorohozhytska St., 04112 Kyiv, Ukraine

tel: +380675020352

e-mail:yesyur69@gmail.com

Received: 11.08 .2019

Accepted: 15.04 .2020

A - Work concept and design, B - Data collection and analysis, C - Responsibility for statistical analysis,

D-Writing the article, $\mathbf{E}$-Critical review, $\mathbf{F}$ - Final approval of the article 